EDUHEM 2018

VIII International conference on intercultural education and International conference on transcultural health: THE VALUE OF EDUCATION AND HEALTH FOR A GLOBAL, TRANSCULTURAL WORLD

\title{
FORMED EMIGRATION: A QUALITATIVE STUDY ABOUT SPANISH GRADUATED EXPERIENCES AND ADAPTATION ABROAD
}

\author{
Inmaculada López-Francés (a)*, Carmen Carmona (b), Simran Vazirani Mangnani (b), Nerea \\ Hernaiz-Agreda (c), Maria Jesús Benlloch Sanchís (b) \\ *Corresponding author
}

(a) University of Valencia, Department of Educational Theory. Av. de Blasco Ibáñez, 30, 46010, Valencia, Spain. *Email: Inmaculada.Lopez-Frances@uv.es

(b) University of Valencia, Department of Research Methods and Educational Diagnosis.

(c) University of Valencia, Department of Didactics and School Organization

\begin{abstract}
In the past few years, Spain has gone through an economic recession that has impeded the development of professional opportunities for young graduates. Consequently, there is an increasing migration of young graduates across borders to work abroad. The aim of this qualitative research, carried out through a case study, is to examine the experiences of Spanish graduates in developing a professional career abroad, specifically in Germany. Ten interviews were analyzed through inductive content analysis.Our results indicate that the migration of young Spaniards to work abroad is the result of economic and / or professional need rather than choice. Furthermore, language proficiency was found to be a key to achieving consistent training, an employment indicator linked to their personal training. Some of the main barriers in the host country are related to language knowledge, bureaucratic issues, friendly relations with native people, climatology, and cultural distance, as well as the existence of German-Spanish and SpanishGerman stereotypes that make everyday situations difficult. Finally, it was observed that previous mobility, fluency in the language, mastery of technological resources, knowledge about the country, flexibility/openness, and having friendships/contacts in the host country are considered key elements in successful integration.
\end{abstract}

(C) 2019 Published by Future Academy www.FutureAcademy.org.UK

Keywords: Adaptation, competences, young graduates, labour market. 


\section{Introduction}

In the past few years, Spain has gone through an economic recession that has generated a framework of labour relations characterized by greater requirements, low economic compensation, a regression in labor rights, and a high rate of unemployment (Álvarez, 2015; Montalvo, 2009; Pochman, 2011; Reig, 2010). According to the INE (2017), the percentage of general unemployment is $18.63 \%$, and $42.92 \%$ in youth. In this context, young people perceive themselves as a vulnerable or precarious group (Rodríguez, 2017). Graduate students do not think they have the possibility of finding a job that allows them to reach a minimally stable life, and they do not have professional opportunities or perspectives to develop in the Spanish state, despite their titles and merits. This experience is reflected in the youth Eurobarometer (2014), where $57 \%$ of young Europeans (16-30 years) claim to feel marginalized and excluded from the social and economic life of their respective countries. In the case of Spain, this percentage increases significantly to $84 \%$.

According to Gutierrez and Albarracín (2008), the youth population has become one of the main groups that suffer the hardest working conditions, precariousness, unemployment, and the erosion of wages, in other words, a deterioration in their quality of life and health. Considering these circumstances, young graduates perceive the idea of emigrating as a way to develop their labour-vital project. On this topic, Santos (2013) shows that international mobility is an added value in higher education. However, "graduate students are not the only ones responsible for their employability because it is a social process that depends on other variables such as -the job market, social class, etc.- and is not just based on individual characteristics and achievements" (Santos 2013, p. 135).

Thus, the questions are: Is this qualified migration forced, or is it a choice? Is it exclusively a product of the socioeconomic crisis context in Spain, or is it related to other issues? What are the factors that affect the migration decision? Based on these questions, other inquiries inevitably arise: Have young graduates been adequately prepared, educated, and trained to work abroad? How do they adapt and settle in the host country? Do they have a job related to their educational background, or are they living in precarious situations? Do their expectations of mobility coincide with reality? What are the main difficulties they have in developing their professional project? These are key questions in understanding this phenomenon and achieving greater knowledge about this process.

\section{Problem Statement}

The research aims to analyse the factors related to young graduates' decision to emigrate and the way they perceive their personal and professional project in the host country.

\subsection{Qualified migration: young entrepreneurs or exiled?}

At present, migrations are at the centre of political, scientific and academic attention (Carmona, Marhuenda, Hernaiz-Agreda, \& Navas, 2018; Domingo \& Blanes, 2016; Navarrete-Moreno, CuencaGarcía, Díaz-Catalán, Díaz-Chorne, \& Zuñiga, 2014; Santos, 2013). Specifically, in the Spanish context, we find different discourses that attempt to answer the questions raised. At the governmental level, graduates' migration is a question of adventure, with a formative nature and even enjoyable. There is no 
migratory flow that responds to economic reasons; instead, it is a fundamental value in the training of young graduates. To avoid concepts such as escape or exile, there is discussion of international mobility. Along the same lines, we find policies sponsored by the EU. Musselin's research (2004) provides evidence that European policies focus intensely on student promotion, academic mobility, and the preparation of networks and research plans across the EU.

Traditionally, the European Union has no authority in the area of higher education in the form of mandatory policy reforms because it applies the principle of subsidiarity. However, the EU can stimulate action plans with higher education policy in the Member States based on the principle of subsidiarity. A clear example of this is the implementation of the ERASMUS programme, which allows European students to study or work in another European country for a period of time during their studies. De Oude (2014), in his study, shows that the EU focuses on research related to "European identity" in order to create cultural awareness and promote the future movement of young people and their skills by presenting mobility as an added value to achieve employment.

University discourses are steeped in these European policies, highlighting international mobility as a requirement and an added value to make a successful transition from the academic world to the job world. The idea that mobility is a way to develop the skills and competences acquired in the academic training is a naturalized idea, accepted in academic, business, and governmental discourses. However, how is this assumption perceived by young migrants?

The young migrants themselves (organized in collectives such as Juventud sin Futuro o Marea Granate) link the growth of emigration mainly to the effects of the economic crisis, government policies, and public spending cuts. They define themselves as "economic exiles", "expelled" from their own country by economic and labour policies that have generated uncertainty, unemployment, or instability that keeps them from developing their own life projects (Santos, 2013). They recognize that mobility enriches and produces the development of specific skills and abilities, but it is associated with precariousness, a lack of training in the skills that are considered keys to professional success, and the feeling of being forced, without any another alternative, to migrate in order to develop (Rodríguez, 2017). They do not demonize mobility itself, but they also stress that they do not idealize it or distort it to avoid a substantive discussion: job insecurity.

This confrontation in the discourses about emigration is not new, as it was already present a century ago, coinciding with the first great migratory wave. The differentiating element is the high educational level of the population leaving the country and the use of communication technologies that break the structures space-time and convert the far away in close (Navarrete-Moreno et al., 2016). The Spanish job market was already problematic before the economic crisis. However, from 2008 on, the access to the labour market has been extremely difficult, with an extraordinary impact on young people, immigrants, and unskilled workers (Malo \& Cueto, 2014). Carmona et al. (2018) presented a description of the development of the Spanish labour market where they revealed a high rate of youth unemployment, temporary (unwanted) work and high polarization of youth employment, higher vulnerability of young people during the crisis, a mismatch between the qualifications and the job position, and the lack of proper institutional structure in the labour market. They concluded that "For all of them, migration is no longer just an option, but the only way to develop a professional career" (Carmona et al., 2018, p.7). 


\subsection{The graduate migrant: integration process}

This study focuses on trying to understand how migrants established their labour project in the host country, which adaptation strategies they activated, and how the competences acquired during their academic education influenced their successful insertion. It is assumed that the formation of these young migrants brings them closer to good levels of integration, despite economic difficulties, climate, differences in customs or language (González-Ferrer, 2013).

In the integration process, the spaces experienced and perceived by young migrants do not remain static. They are fluid, constructed according to the socio-cultural interactions they are experiencing. This process is developed and modified based on the way conflicts between their expectations and the real situations arise and are resolved, as well as their social and work status, the language barrier, and the attitudes shown by the host society towards them (Rodriguez, 2017). How do they face the obstacles of the migration process or culture shock? What obstacles do they encounter and how do they adapt to them? In part, achieving this integration depends on the skills acquired and mastered by young people.

In this context, a main priority appears at the academic level, where these young people are trained to achieve successful development. The European Commission (2010) insists on the need to acquire key competences as an indispensable condition for individuals to achieve personal, social, and professional development that meets the demands of a globalized world and makes economic development linked to knowledge possible. To achieve this, a combination of knowledge, skills, and attitudes are necessary and appropriate in the context of personal fulfilment and development, social inclusion, active citizenship, and employment. DeSeCo project defines competence as "the ability to respond to complex demands and carry out diverse tasks in an appropriate manner". Competition "involves a combination of practical skills, knowledge, motivation, ethical values, attitudes, emotions, and other social and behavioural components that are mobilized together to achieve effective action".

Therefore, the acquisition of certain competences is essential in order for graduates, regardless of the importance of the country of destination and the reasons for the migration, to be integrated in the host country. Different personal, social, and professional scenarios can activate this "know-how" that leads to competences. The European Commission (2010) states that these competences are: communication in the native and foreign language, computer skills, reading, writing, and basic knowledge of mathematics and science, as well as horizontal competences such as learning to learn, social and civic responsibility, initiative and entrepreneurship, cultural sensitivity, and creativity.

\section{Research Questions}

In the present research, we outline the following questions to answer:

- What factors are the most relevant to Spanish young people in making the decision to migrate?

- Is this phenomenon a product of the socioeconomic situation produced by the Spanish economic crisis?

- How do young graduates experience the integration process once they have settled in the host country?

- What obstacles do they encounter and how do they adapt to them?

- What are the necessary competences to achieve successful integration? 
- Answering these questions will provide a fair picture of this topic and might reveal a deeper understanding of qualified Spanish migration.

\section{Purpose of the Study}

The main purpose of the current research is to understand the perspectives of young Spanish emigrants regarding their decision and motives for leaving the country, how they prepare for migration, and how they perceive their integration into the host country, in terms of their new status as immigrants, taking into account factors as general hassles, work, language, contacts, and friends. In addition, competences that are relevant to this process are analysed, as well as challenges they experienced while adapting to life in the new country, expectations, and their level of satisfaction with their migration choice and current situation.

\section{Research Methods}

This study is based on a qualitative methodology, where in-depth semi-structured interviews were conducted to understand the experiences of Spanish graduates who had decided to pursue a professional career in Germany. According to Johnson (2002), in-depth interviews help to seek deeper information and knowledge about experiences, values and decisions, cultural knowledge, or viewpoints, and they are useful for gathering different perspectives of individuals involved in the sameactivity.

The participants were selected based on the following: 1) Spanish nationality, 3) graduated, and 3) moved to Germany in the last five years. Participants were 10 Spanish women with graduate degrees in various fields, and their ages ranged between 23 and 39 years. The participants worked and lived in Germany, in particular in Berlin. Interviews were held face-to-face for 30 minutes in Germany, and they were recorded and transcribed. Participants were selected through snowball sampling. This method starts with one or few individuals and expands due to links from the initial contacts. In our case, the initial contact was through a virtual network.

The interview design started with sociodemographic questions (such as age, qualification, city of origin) followed by questions related to characteristics before leaving the country (work experience, reason for migration, which information they knew about destination country, did they have adequate language skills, how did they prepare for the migration, how did they ensure adequate points of contact). The interview gradually moved onto questions related to more recent events, such as their process of adaptation to the new environment and the barriers and sociocultural differences found, about their support system, work experience and competences required. The last few questions provide information about expectations, asking them if they would finally settle in the foreign country and if they have suggestions for future migrants.

The purpose of the interview was to understand the interviewees' migration projects, as well as their motives for migration, competences, support networks, barriers, adaptation process in a new context, and work environment. Some of the questions were: What was the main purpose of moving to Germany? What languages do you speak? Did you have a point of contact in Germany before coming? What barriers do you 
face? Certain work-related questions were: How did you look for a job? How is the job related to your bachelor's degree? What were the job characteristics, difficulties found, and competences required?

The authors rigorously and systematically analysed the interview transcripts using ATLAS.ti (a qualitative data analysis software tool), and they categorized the data thematically through an inductive approach. This approach helps to identify themes or codes directly from the data and enhance the reliability of the research (Cho \& Lee, 2014).

\section{Findings}

The results show different experiences of young Spanish graduates in their process of adaptation to a new country and work environment. Most of the participants had things in common related to their motives for migration, importance of the competences, especially related to language competence, and similar difficulties dealt with in the process. Based on their experience, they also shared some recommendations for better adaptation.

\subsection{Motives for migration}

The data on unemployment, temporary jobs, and low salaries in Spain form the perfect combination for highly qualified youth migration. In addition, a labour market that does not create opportunities for young people aggravates the situation (Santos, 2017). In our results, most of the interviewees migrated to Germany for the previous reasons, better professional and economic opportunities:

"The situation in Spain is still precarious. At work, many young people have a degree, but we cannot find the job we want" (Sara, f, 24).

"I realized I was working a lot, doing the same things as other people abroad, and my salary was a maximum of 1500 euros and sometimes 1200 euros" (Patricia, f, 39).

However, in two of the cases, participants travelled abroad for better job opportunities for their partners.

\subsection{Relationship and Support networks}

Most of the participants said they had relationships or contacts with people from different cultures. Moreover, a few of them said they had a multicultural environment in their jobs, which helps them to stay in contact not only with local people, but also with people from around the world.

Social networks or blogs are important in the mobility process, not only before arriving in the host country, but also during the process, and sometimes even after returning home. They offer relevant, interactive, and close information that helps not only to achieve knowledge about the country, but also to make contacts and gain real support from other experienced compatriots:

"I met Patricia in Internet [...] and also some other Spanish people" (Tere, f, 29).

With regard to support networks, some of the interviewees received economic support from their parents, public institution, friends, and partners. Additionally, some of them said they had strong social 
support from family members, the ingroup (Spanish people), the outgroup (German people), other immigrants, and their partner. However, many of them felt they did not have any social support:

"I am alone; my family and friends have returned back home" (Alejandra, f, 23)

According to the participants, many of them received support in their job from other colleagues, the company, the boss, or even their partner:

"When it comes to writing an email saying: hello, I would like to work in your company, he [her partner] does it for me" (Aida, f, 29).

\subsection{Language as a key factor}

Nowadays, as Carmona, Marhuenda, Hernaiz-Algreda and Navas (2018) explain, it is hard to find a proper job and fully integrate in Germany if one only knows some English as a foreign language. For this reason, some of our interviewees searched for different ways to learn the host language:

"We searched for an academy and everything to learn the language because without the language you cannot manage here. Here everyone knows how to speak English, but it's not the same. You have to know [German] the language if you want to integrate" (Aida, f, 29)

According to the interviewees, both high qualifications and good knowledge of the German language are relevant in finding a proper job:

"The sooner you learn the language, the sooner you will find work related to your degree because you have good qualifications, and the only problem is the language" (Angela, $\mathrm{f}$, age).

\subsection{Competences}

Some of the participants shared some personal qualities, such as: predisposition to mobility, social skills, initiative in making friends, flexibility, autonomy/independence, open-mindedness, extroversion, and emotional stability. All these qualities helped them in the process of adaptation to a new context and work environment. Moreover, the interviewees noted personal growth during this process, not only in the previously mentioned qualities, but also in their language competence, cultural empathy, and ability to adapt to a different environment, work in an international context, face new situations, solve problems by themselves, and develop more perseverance:

"Be very positive and have a lot of patience because it takes a lot of time here, and it's necessary to have patience that everything will go well. Here at the beginning we have to adapt; we are the ones who come from outside, and so we have to adapt to their mentality, to their way of being, accept it" (Tere, f, 29).

\subsection{Sociocultural differences and barriers}

All the participants have faced some common problems related to the cultural distance. Spanish participants found German people distant, direct, introverted, and less affective, and they felt that German people wanted everything done in a certain way. In addition, some of the participants had experienced or heard some stereotypes about Spanish people, such as: 
"The first thing the Germans are going to tell you is related to the nap as a way to work as little as possible" (Cristina, $\mathrm{f}$, age).

The participants also agreed about having some barriers related to bureaucratic issues, climatology, and, especially, searching for specialized work in the field they needed:

"I was feeling a little bad because I didn't find a job giving classes, and it was a job that I needed. I went to each academy to give them my CV face to face in case they needed someone, but they didn't select me, and in the gift shop where I was going to work, they said that they didn't need me anymore" (Belén, f, 25).

\subsection{Recommendations for better adaptation}

The participants, through their experience, shared some mobility recommendations for future migration. Some of these recommendations are: learn the local language, know about the host culture before arrival, have good qualifications, interact with the local people, have pre-existing financial backing, and search for a person with information about the host country, specific things related to work, or the mindset/mentality of the local people:

"I think if you don't know any German person you will get lost, or at least someone who has lived many years in Germany, or else you will misunderstand everything, as happened to me in my work" (Patricia, f, 39).

\section{Conclusion}

The data and research consulted suggest that we are facing an economic and labour migration, not a leisure or adventurous one, that responds to the existence of a precarious labour market and deteriorating labour rights (Gutiérrez \& Albarracín, 2008; Álvarez, 2012; Pochman, 2011; Reig, 2010). This context forces young people to cross borders. Santos (2013) explains that graduates are not the only ones responsible for their employability, variables such as the job market and social class are also responsible.

Work migrants' adaptation processes are complex and depend on multiple factors, such as the level of qualification, the command of the language, and the demand for that specific work in the host country (Santos, 2016). To this, we add the importance of having social support networks, contacts, and certain competences necessary to overcome the difficulties in the destination country (Rodríguez, 2017). Thus, the European Commission (2010) insists on the need to acquire certain competences as an indispensable condition to achieve personal, social, and professional development of a globalized world. In addition, social networks are very important for seeking information, contacts before arriving in the host country and during the process and they serve as tools to stay in contact with family and friends (Navarrete-Moreno et al., 2016). According to Ellison, Steinfield, and Lampe (2007) social network sides helps to establish or maintain connections with each other.

In this context, the migrant, after continuous interaction with people from different countries in a plurality of social and labour spaces, emphasizes the need to possess certain competences, such as the ability to adapt to a new environment, face new situations, and solve problems by themselves (González-Ferrer, 2013). Talf (1977) in Winkelman (1994) also suggest that immersion to another country requires, among 
other things, adaptation in the personality; and acquiring culture knowledge, skills, attitudes and perceptions. The results show that social skills, flexibility, emotional stability, and open-mindedness are important when it comes to adapting better to the host country and work environment. Various studies (Van der Zee \& Van Oudenhoven, 2000, 2001, 2013; \& Carmona, Van der Zee, Van Oudenhoven \& HernaizAgreda, 2016) also reveals that a multicultural personality (i.e., cultural empathy, open-mindedness, emotional stability, flexibility, and social initiative) is directly linked to success in an intercultural context. Language is a key factor in integration because it facilitates mobility, communication and creates deep relationships (Vazirani, et al., 2018), it makes it possible to obtain work and professional opportunities and it helps in dealing with problems.

Finally, before migrating abroad, as the interviewees explained, in addition to learning the language, it is necessary to know about the culture of the host country, seek contacts, and have certain economic stability. Moreover, if the main objective is to search for a job, it is important, in addition to having good qualifications, as Carmona et al. (2018) explain, to know about the labour market of the specific city in Germany, because it can vary from city to city, and about the unemployment percentage, the demands of that particular work, how to search for a job, and the cost of the living and other expenses.

\section{References}

Carmona, C., Marhuenda, F., Hernaiz-Agreda, N., \& Navas, A. (2018). Educated for migration? Blind spots around labor market conditions, competence building, and international mobility. European Educational Research Journal, 0 (0), 1-16.

Carmona, C., Van der Zee, K. I., Van Oudenhoven, J. P., \& Hernaiz-Agreda. (2016). Intercultural Competences and Self-Identity as Key Factors to Adaptation. In C. Roland-Lévy, P. Denoux, B. Voyer, P. Boski \& W. K. Gabrenya Jr. (Eds.), Unity, diversity and culture: Research and Scholarship Selected from the 22nd Congress of the International Nagoya, Japan: Association for Cross-Cultural Psychology. .

Cho, J., \& Lee, E. (2014). Reducing confusion about grounded theory and qualitative content analysis: Similarities and differences. The Qualitative Report, 19 (32), 1-20.

De Oude, C. (2014). The added value of international student mobility in the recruitment and selection processes of young academics in the labour market (Doctoral Dissertation). University of Twente, Netherlands.

Domingo, A., \& Blanes, A. (2016). La nueva emigración española: ¿una generación perdida? -Panorama Social, 23, 157-178.

Ellison, N. B., Steinfield, C., \& Lampe, C. (2007). The benefits of Facebook "friends:" Social capital and college students' use of online social network sites. Journal of Computer-Mediated Communication, 12(4), 1143-1168.

Eurobarometer (2014). Unemployment statistics. Retrieved from: http://ec.europa.eu/eurostat/statisticsexplained/index.php/Unemployment_statistics\#Recent_developments_in_unemployment_at_a_Eu ropean_and_Member_State_level.

European Commission (2010). Geographical and labour market mobility. Report for the Special Eurobarometer/Wave 72.5 - TNS Opinion \& Social. (Report no. 337). Retrieved from: http://ec.europa.eu/commfrontoffice/publicopinion/archives/ebs/ebs_337_en.pdf

González-Ferrer, A. (2013). La nueva emigración española. Lo que sabemos y lo que no", Zoom Politico, 18, 1-18.

Gutiérrez, E., \& Albarracín, D. (2008). Financiarización y economía real: perspectivas para una crisis $\begin{array}{llll}\text { civilizatoria. Viento } & \text { sur. } & \text { Retrieved }\end{array}$ http://www.vientosur.info/documentos/Financiarizacion.pdf 
Instituto Nacional de Estadística (2017). Nota de prensa. Encuesta de población activa. Retrieved from: http://www.ine.es/daco/daco42/daco4211/epa0416.pdf

Johnson, J. (2002). In-Depth Interviewing. In J. Gubrium \& J. Holstein (Eds.). Handbook of interview research: Context and method (pp.103-120). USA: Sage.

Malo, M.A., \& Cueto, B. (2014). El bloqueo de la entrada en el mercado de trabajo español durante la recesión: ¿Sólo un problema de los jóvenes?. Fundación Foessa. Retrieved from: http://www.foessa2014.es/informe/uploaded/documentos_trabajo/16102014141943_9835.pdf

Montalvo, J. (2009). Financiación inmobiliaria, burbuja crediticia y crisis financiera: lecciones a partir de la recesión de 2008-2009. Papeles de Economía Española, 122, 66-85.

Musselin, C. (2004). Towards a European academic labour market? Some lessons drawn from empirical studies on academic mobility. Higher Education, 48(1), 55-78.

Navarrete-Moreno, L. Cuenca-García, C., Díaz-Catalán, C., Díaz-Chorne, L., \& Zuñiga, R. (2014). La emigración de los jóvenes españoles en el contexto de la crisis: Análisis y datos de un fenómeno difícil de cuantificar. Madrid: INJUVE.

Organización para la Cooperación y el Desarrollo Económico (2003). La definición y selección de competencias clave. Resumen ejecutivo. Retrieved from: www.OECD.org/edu/statistics/deseco

Pochmann, M. (2011). La fuga de cerebros y la nueva división internacional del trabajo. Nueva Sociedad, 233, 98-113.

Rodríguez, R. (2017). La emigración de jóvenes universitarios españoles en el actual contexto de crisis: procesos y factores migratorios (Doctoral Dissertation). Universidad de Granada, Spain.

Santos, A. (2013). Fuga de cerebros y crisis en España: los jóvenes en el punto de mira de los discursos empresariales. Areas. Revista Internacional de Ciencias Sociales, 32, 125-137.

Santos, A. (2016). Review of the book ¿Por qué te vas? Jóvenes españoles en Alemania. Reis, 155, 161165.

Talf, R. (1977). Coping with unfamiliar cultures. In N. Warren (Ed). Studies in cross-cultural psychology, (pp. 125-153). London, England: Academic Press.

Van der Zee, K. I., \& Van Oudenhoven, J. P. (2000). Psychometric qualities of the Multicultural Personality Questionnaire: A multidimensional instrument of multicultural effectiveness. European Journal of Personality, 14(4), 291-309.

Van der Zee, K. I., \& Van Oudenhoven, J. P. (2001). The Multicultural Personality Questionnaire: Reliability and validity of self- and other ratings of multicultural effectiveness. Journal of Research in Personality, 35(3), 278-288.

Van der Zee, K., \& van Oudenhoven, J. P. (2013). Culture shock or challenge? The role of personality as a determinant of intercultural competence. Journal of Cross-Cultural Psychology, 44(6), 928940.

Vazirani, S., Carmona, C., Vidal, J., Hernaiz-Agreda, N., López-Francés, I., \& Benlloch-Sanchis, M.J. (2018). International Students' Integration in Classroom: Strategies and Support by Teachers and Local Students in Higher Education. In M. Karasawa, M. Yuki, K. Ishii, Y. Uchida, K. Sato, \& W. Friedlmeier (Eds.), Venture into cross-cultural psychology: Proceedings from the 23rd Congress of the International. Nagoya, Japan: Association for Cross-Cultural Psychology.

Winkelman, M. (1994). Cultural shock and adaptation. Journal of Counseling \& Development, 73(2), 121- 126. 